\title{
Health-Related Quality of Life in Patients 7 Months After a Myocardial Infarction: Factors Affecting the Short Form-12
}

\author{
Christopher R. McBurney, Pharm.D., Kim A. Eagle, M.D., \\ Eva M. Kline-Rogers, M.S., Jeanna V. Cooper, M.S., Obli C. M. Mani, MBBS, \\ Dean E. Smith, Ph.D., and Steven R. Erickson, Pharm.D.
}

We assessed patients' health-related quality of life after myocardial infarction and identified related variables. Clinical data were obtained retrospectively from medical records of consecutive patients admitted to a Midwestern university-affiliated medical center with diagnosis of myocardial infarction from July 1999-July 2000. Telephone interviews 7 months after discharge were made to administer the Short Form-12 (SF-12) and obtain patient, disease, drug, and intervention data. Complete information was obtained from 200 patients (mean age $63.4 \pm 13.1$ yrs, 68\% men). The mean Physical Component Summary (PCS)-12 score was $40.6 \pm 12.0$, and the mean Mental Component Summary (MCS)-12 score was $52.1 \pm 10.0$. Based on univariate analyses, low PCS-12 scores were associated with women; non-Q-wave infarctions; greater number of illnesses; history of myocardial infarction, chronic heart failure (CHF), transient ischemic attack (TIA), renal disease, peripheral vascular disease, or percutaneous coronary intervention $(\mathrm{PCl})$; rehospitalization during the interim period; and unscheduled $\mathrm{PCI}$ since index myocardial infarction. Low MCS-12 scores were associated with age below 65 years, low overall self-reported drug therapy compliance, low self-reported compliance with angiotensin-converting enzyme inhibitor and lipid-lowering therapy, no history of coronary artery bypass graft, and no stress test since index myocardial infarction. A multivariate regression model for PCS-12 kept the following variables: greater number of illnesses, history of CHF or TIA, and rehospitalization since index myocardial infarction. The MCS-12 model contained age below 65 years, low overall compliance, and low compliance with lipid-lowering therapy. Further work is necessary to determine noncardiovascular predictors of quality of life and whether interventions for these patients will result in improved quality of life.

(Pharmacotherapy 2002;22(12):1616-1622)

After a myocardial infarction, patients often experience physical and emotional effects related to the event that impair functioning to the point of interfering with housework, work for pay, social life, and other important activities. They may experience anxiety and depression that were not present before the event, which may exacerbate existing conditions. ${ }^{1-3}$ General and disease-specific instruments may capture patient- reported outcomes such as health-related quality of life (HRQOL). Health-related quality of life complements physiologic and clinical markers of cardiovascular disease and/or its treatment, and has been studied in patients with myocardial infarction. ${ }^{4-17}$ Many of these were controlled clinical trials assessing the effectiveness of an intervention. Such studies provide a way to move from measuring outcomes to improving 
care for groups and individual patients.

When studying population-based HRQOL, patient, disease, treatment, and health care delivery system are all possible influences. In patients who experienced a recent myocardial infarction, these variables may include demographics, severity of illness, revascularization procedures, drug therapy, and comorbidity. For example, cardiac as well as noncardiac problems were associated with the two summary measures of the Short Form (SF)-36, a general HRQOL instrument, in a predominantly male population 7 months after discharge for acute coronary syndrome. ${ }^{6}$ The SF-12, a shorter version of the SF-36, was mailed to patients who had had a myocardial infarction 2 years earlier and revealed that chest pain and a history of smoking at the time of infarction were associated with low HRQOL. ${ }^{5}$

Data pertaining to cardiac care before, during, and after hospitalization for myocardial infarction, together with patient and provider characteristics, are often available for qualityassurance programs. The addition of patientreported outcomes such as HRQOL broaden the scope of assessment of care. We evaluated the relationship between HRQOL and common patient, disease, and treatment-intervention variables 7 months after discharge for treatment of acute myocardial infarction.

\section{Methods}

This was a cross-sectional study of patients aged 18 years and older with the primary or secondary discharge diagnosis of acute myocardial infarction (International Classification of Diseases [ICD]-9 code 410) between July 1, 1999, and July 31, 2000. Those who were alive at the time of the follow-up interview constituted the study sample. They had to understand and be able to communicate in English so as to participate in the telephone survey. There were no other exclusion criteria. Patient demographic and selected cardiac history data were used for a

From the Division of Cardiology, Department of Internal Medicine, University of Michigan Medical Center (Drs. McBurney, Eagle, Mani, and Smith, Ms. Kline-Rogers, and Ms. Cooper), and the College of Pharmacy, University of Michigan (Dr. Erickson), Ann Arbor, Michigan.

Presented as a poster at the annual meeting of the International Society for Pharmacoeconomics and Outcomes Research, Arlington, Virginia, M ay 20-23, 2001.

Address reprint requests to Steven R. Erickson, Pharm.D., University of Michigan, College of Pharmacy, 428 Church Street, Ann Arbor, MI 48109-1065; e-mail: serick@umich. edu. nonresponse bias assessment of potential respondents who were assumed to be alive but whom investigators were unable to contact. The study was approved by the human investigations committee of the affiliated medical school.

\section{Data Collection}

A cardiology nurse clinician and two cardiac medicine fellows obtained information regarding patient demographics, medical history, and hospital course by reviewing medical records. This information was entered into a database that is used for quality-assurance projects and reports. An investigator contacted patients at home by tel ephone approximately 6-7 months after discharge and administered the survey. At least five attempts during different times of the day were made to contact patients.

\section{Patient and Disease Characteristics}

Patient and disease characteristics were obtained by both chart review and patient selfreports during telephone interviews. Age, sex, race, marital status, number of other documented illnesses, type of myocardial infarction, ejection fraction at the time of discharge or shortly afterward, and drugs prescribed at discharge were obtained from medical records. Body mass index (BMI) was calculated from recorded height and weight.

\section{Treatment Characteristics}

Medical history before admission was obtained from records and included diagnoses and cardiacrelated procedures. Procedures included occurrence at any time of coronary artery bypass surgery ( $C A B G$ ), percutaneous transluminal coronary angioplasty (PTCA) or percutaneous coronary intervention $(\mathrm{PCI})$, or cardiac catheterization. The same information was obtained from medical records of hospitalization for the index myocardial infarction. Events and procedures that occurred between discharge and telephone survey were recorded during telephone interviews; for example, rehospitalization for cardiac problems, occurrence of stroke, scheduled and unscheduled revascularization procedures (e.g., PCI, CABG), scheduled or unscheduled cardiac catheterization, and exercise stress tests.

A drug list was constructed during interviews as reported by patients. Agents relevant to this analysis were antiplatelet and/or anticoagulant 
drugs, $\beta$-blockers, angiotensin-converting enzyme ( $A C E$ ) inhibitors (or angiotensin II receptor blockers), and lipid-lowering drugs. Self-reported compliance with therapy was assessed by a 4 -item scale. ${ }^{18}$

\section{Health-Related Quality of Life}

Health-related quality of life was measured with the SF-12, a generic measure of health status for use in population surveys. ${ }^{19}$ It includes one or two items from each of the eight health concepts measured by the SF-36 and contains two summary measures of functioning and wellbeing: Physical Component Summary (PCS-12) and Mental Component Summary (MCS-12); these provide the same information as the SF-36 summary measures. I tem scores are coded, summed, and transformed to a scale ranging from 0 (worst health status) to 100 (best health status), and adjusted to norm-based scaling for a final score for each health concept. The questionnaire uses a 4-week recall period.

\section{Data Analyses}

Summary statistics were presented as frequencies and percentages or as means, medians, and SD. Univariate associations between HRQOL scores (PCS-12, MCS-12) and nominal explanatory variables were examined with the Wilcoxon rank sum test. Age, BMI, and number of other illnesses were recoded as univariate variables based on the median split of variable data. Ejection fraction data were split at $40 \%$.

Multivariate linear regression was conducted to determine the strength of association between patient and disease characteristics and the PCS12 and MCS-12 scores. Spearman's correlation was performed to identify highly related explanatory variables. If the $\mathrm{R}$ value was greater than 0.4 , the pair of variables and correlation pattern with other variables were examined and a decision was made to leave or remove it from the regression model. Variables "history of catheterization before the reference myocardial infarction" and "occurrence of catheterization during the interim period (between discharge and survey)" were removed due to high correlation with a number of other explanatory variables.

Two groups of explanatory variables were created. The first group consisted of patient demographics, prehospitalization history and procedures, and hospitalization-related data. The second group entered into the regression model consisted of events that occurred between discharge for the reference myocardial infarction and time of the survey. Noncontributory explanatory variables were eliminated from the model using backward stepwise elimination of variables with a $p$ value greater than 0.1 . The final regression models were developed by stepwise backward elimination with inclusion variables having a $p$ value of 0.05 or less. A p value of 0.05 was chosen to develop a parsimonious set of predictor variables for the final models. Two separate models were developed, one for each dependent variable, PCS12 and MCS-12. SAS (SAS Institute, Cary, NC) was used for analyses.

\section{Results}

During the study period 258 patients were discharged from the hospital. Of these, 26 patients (10\%) were lost to follow-up or died, and 32 (12\%) had incomplete information for analysis, leaving 200 (78\%) as the sample (Table $1)$. Nonresponse bias assessment showed that more nonrespondents than respondents had a history of transient ischemic attack (TIA), diabetes, renal insufficiency, peripheral vascular disease, $C A B G$, and previous myocardial infarction.

Mean follow-up was $7.3 \pm 1.5$ months. Almost all patients had at least one comorbidity at the time of the index myocardial infarction. Most common were angina, smoking, hyperlipidemia, and hypertension. Many patients (32.5\%) had a history of myocardial infarction. Over two thirds had an ejection fraction of $40 \%$ or greater at the time of or immediately after discharge for the index myocardial infarction. Revascularization procedures were performed during hospitalization or during the interim (discharge to survey) in $71 \%$ of patients. The mean PCS-12 score was 40.6, and mean MCS-12 score was 52.1.

Table 2 shows results of univariate analyses that were statistically significant. Significant differences in PCS-12 scores were observed based on sex, type of myocardial infarction, number of other illnesses, history of myocardial infarction, history of chronic heart failure (CHF), history of TIA, history of renal disease, history of peripheral vascular disease, history of $\mathrm{PCl}$, rehospitalization for heart disease since index myocardial infarction, and unscheduled $\mathrm{PCI}$ since index infarction. Significant differences in MCS-12 
Table 1. Characteristics of Respondents

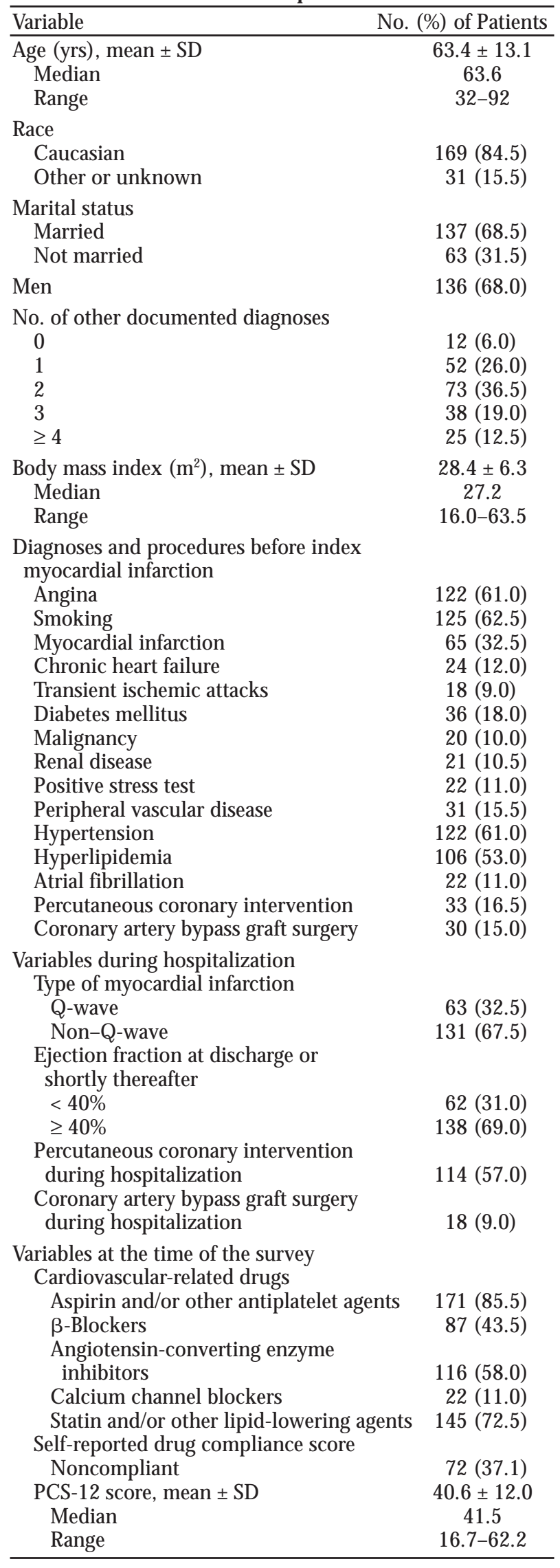

Table 1. Characteristics of Respondents (continued)

\begin{tabular}{lc}
\hline Variable & No. (\%) of Patients \\
\hline MCS-12 score, mean \pm SD & $51.1 \pm 10.0$ \\
Median & 55.3 \\
Range & $24.1-68.8$ \\
Events between discharge after index & \\
myocardial infarction and survey & \\
Rehospitalization for cardiac problem & $60(28.2)$ \\
Stroke & $3(1.4)$ \\
Scheduled percutaneous coronary & $16(7.6)$ \\
intervention & $8(3.8)$ \\
Scheduled coronary artery bypass graft & \\
Unscheduled percutaneous coronary & $8(3.8)$ \\
intervention & $1(0.5)$ \\
Unscheduled coronary artery bypass graft & $13(10.0)$ \\
Myocardial infarction & $44(24.7)$ \\
Stress test & \\
\hline PCS = Physical Component Summary; MCS = Mental Component \\
Summary.
\end{tabular}

scores were seen based on age, history of CABG, self-reported drug therapy compliance, and two drugs, lipid-lowering agents and ACE inhibitors.

Regression analysis for the PCS-12 model is presented in Table 3. The final PCS-12 model had an adjusted $R^{2}$ of 0.21 and model coefficient of 0.48 . Explanatory variables included in the final PCS-12 model were number of comorbidities, rehospitalization due to heart disease during the interim period, and history of $\mathrm{CHF}, \mathrm{TIA}$, and $\mathrm{PCI}$ before the index myocardial infarction. Histories of $\mathrm{CHF}, \mathrm{TIA}$, and $\mathrm{PCI}$ (which indicates existing coronary artery disease) were similarly influential, and when present before the index myocardial infarction were related to lower PCS-12 scores. Also related to lower PCS-12 scores were greater number of other illnesses and hospitalization since discharge for the index infarction.

Table 4 shows regression analysis for the MCS12. The MCS-12 regression model had an adjusted $R^{2}$ of 0.13 and a regression model coefficient of 0.38 . Three explanatory variables were included in the final model: age, selfreported compliance, and lipid-lowering therapy. Older age, greater compliance, and need for lipidlowering therapy were associated with higher MCS-12 scores.

\section{Discussion}

Goals of therapy for patients after myocardial infarction are generally to alleviate symptoms, improve functional abilities, and slow or halt disease progression. The HRQOL provides information pertaining to the effect of the event and/or intervention on the patient's life. Our 
Table 2. Univariate Analyses of Patient and Disease Characteristics and PC S-12 and MC S-12 Scores ${ }^{\mathrm{a}}$

\begin{tabular}{|c|c|c|}
\hline Variable & PCS-12 Score & MCS-12 Score \\
\hline $\begin{array}{l}\text { Age (yrs) } \\
\leq 63.4 \text { yrs } \\
\geq 63.5\end{array}$ & $\begin{array}{c}\text { NS } \\
41.4 \pm 12.9 \\
39.9 \pm 11.0\end{array}$ & $\begin{array}{c}p=0.006 \\
50.0 \pm 10.7 \\
54.1 \pm 8.8\end{array}$ \\
\hline $\begin{array}{l}\text { Sex } \\
\text { Men } \\
\text { Women }\end{array}$ & $\begin{array}{c}p=0.02 \\
42.0 \pm 12.3 \\
37.8 \pm 11.0\end{array}$ & $\begin{array}{l}\text { NS } \\
52.1 \pm 9.8 \\
52.0 \pm 10.4\end{array}$ \\
\hline $\begin{array}{l}\text { Type of MI } \\
\text { Q wave } \\
\text { Non-Q wave }\end{array}$ & $\begin{array}{c}p=0.04 \\
43.2 \pm 11.8 \\
39.7 \pm 12.1\end{array}$ & $\begin{array}{l}\quad \text { NS } \\
52.8 \pm 9.2 \\
51.5 \pm 10.4\end{array}$ \\
\hline $\begin{array}{l}\text { No. of other illnesses } \\
\quad \leq 2 \\
\geq 3\end{array}$ & $\begin{array}{c}p=0.006 \\
42.2 \pm 11.9 \\
37.2 \pm 11.6\end{array}$ & $\begin{array}{l}\quad \text { NS } \\
51.6 \pm 10.1 \\
53.2 \pm 9.7\end{array}$ \\
\hline $\begin{array}{l}\text { Self-reported drug } \\
\text { compliance } \\
\text { Not compliant } \\
\text { Compliant }\end{array}$ & $\begin{array}{c}\text { NS } \\
40.0 \pm 12.3 \\
40.7 \pm 11.8\end{array}$ & $\begin{array}{c}p=0.001 \\
49.8 \pm 10.5 \\
53.6 \pm 9.5\end{array}$ \\
\hline $\begin{array}{l}\text { History of MI } \\
\text { Yes } \\
\text { No }\end{array}$ & $\begin{array}{c}p=0.002 \\
36.8 \pm 11.5 \\
42.5 \pm 11.8\end{array}$ & $\begin{array}{l}\quad \text { NS } \\
52.7 \pm 9.7 \\
51.8 \pm 10.1\end{array}$ \\
\hline $\begin{array}{l}\text { History of TIA } \\
\text { Yes } \\
\text { No }\end{array}$ & $\begin{array}{c}p=0.001 \\
31.2 \pm 8.8 \\
41.6 \pm 11.9\end{array}$ & $\begin{array}{c}\text { NS } \\
49.9 \pm 10.2 \\
52.3 \pm 10.0\end{array}$ \\
\hline $\begin{array}{l}\text { History of renal disease } \\
\text { Yes } \\
\text { No }\end{array}$ & $\begin{array}{c}p=0.003 \\
33.3 \pm 10.2 \\
41.5 \pm 11.9\end{array}$ & $\begin{array}{l}\text { NS } \\
50.6 \pm 8.9 \\
52.3 \pm 10.1\end{array}$ \\
\hline $\begin{array}{l}\text { History of PVD } \\
\text { Yes } \\
\text { No }\end{array}$ & $\begin{array}{c}p=0.02 \\
34.3 \pm 10.9 \\
41.8 \pm 11.9\end{array}$ & $\begin{array}{l}\text { NS } \\
53.2 \pm 9.7 \\
51.9 \pm 10.0\end{array}$ \\
\hline $\begin{array}{l}\text { History of } \mathrm{PCl} \\
\text { Yes } \\
\text { No }\end{array}$ & $\begin{array}{c}p=0.004 \\
35.2 \pm 10.3 \\
41.7 \pm 12.0\end{array}$ & $\begin{array}{l}\quad \text { NS } \\
54.4 \pm 9.6 \\
51.6 \pm 10.0\end{array}$ \\
\hline $\begin{array}{l}\text { History of CABG } \\
\text { Yes } \\
\text { No }\end{array}$ & $\begin{array}{c}\text { NS } \\
36.6 \pm 12.1 \\
41.3 \pm 11.9\end{array}$ & $\begin{array}{l}p=0.001 \\
55.8 \pm 8.2 \\
51.4 \pm 10.1\end{array}$ \\
\hline $\begin{array}{l}\text { Rehospitalized for heart } \\
\text { disease since index MI } \\
\text { Yes } \\
\text { No }\end{array}$ & $\begin{array}{c}p<0.001 \\
35.4 \pm 10.9 \\
42.1 \pm 11.7\end{array}$ & $\begin{array}{l}\quad \text { NS } \\
51.7 \pm 10.4 \\
52.4 \pm 9.9\end{array}$ \\
\hline $\begin{array}{l}\text { Unscheduled } \mathrm{PCl} \text { since } \mathrm{MI} \\
\text { Yes } \\
\text { No }\end{array}$ & $\begin{array}{c}p=0.03 \\
31.3 \pm 13.2 \\
40.7 \pm 11.6\end{array}$ & $\begin{array}{c}\text { NS } \\
50.5 \pm 12.2 \\
52.3 \pm 10.0\end{array}$ \\
\hline $\begin{array}{l}\text { Stress test since MI } \\
\text { Yes } \\
\text { No }\end{array}$ & $\begin{array}{c}\text { NS } \\
42.0 \pm 11.4 \\
40.3 \pm 11.9\end{array}$ & $\begin{array}{c}p=0.006 \\
55.4 \pm 8.1 \\
49.3 \pm 11.3\end{array}$ \\
\hline $\begin{array}{l}\text { Prescribed ACE inhibitors } \\
\text { Yes } \\
\text { No }\end{array}$ & $\begin{array}{c}\text { NS } \\
41.3 \pm 11.4 \\
39.7 \pm 12.8\end{array}$ & $\begin{aligned} p & =0.02 \\
53.2 & \pm 10.3 \\
50.5 & \pm 9.4\end{aligned}$ \\
\hline $\begin{array}{l}\text { Prescribed lipid-lowering } \\
\text { agents } \\
\text { Yes } \\
\text { No }\end{array}$ & $\begin{array}{c}\text { NS } \\
41.2 \pm 12.1 \\
39.6 \pm 11.9\end{array}$ & $\begin{array}{c}p=0.04 \\
53.3 \pm 9.3 \\
49.8 \pm 10.7\end{array}$ \\
\hline
\end{tabular}

PCS = Physical Component Summary; MCS = Mental Component Summary; NS = not significant; $\mathrm{MI}=$ myocardial infarction; $\mathrm{TI} \mathrm{A}=$ transient ischemic attack; PVD = peripheral vascular disease; $\mathrm{PCI}=$ percutaneous coronary intervention; $C A B G=$ coronary artery bypass graft; $\mathrm{ACE}=$ angiotensin-converting enzyme.

The table includes only statistically significant comparisons.

a Data are mean \pm SD.
Table 3. Final Multivariate Linear Regression Model for PC S-12 Scores

\begin{tabular}{|c|c|c|c|}
\hline Variable & $\begin{array}{l}\text { Regression } \\
\text { Coefficient }\end{array}$ & $\begin{array}{l}\text { Standard } \\
\text { Regression } \\
\text { Coefficient }\end{array}$ & p Value \\
\hline History of $\mathrm{CHF}$ & -5.7 & -0.16 & 0.02 \\
\hline History of TIA & -5.7 & -0.14 & 0.04 \\
\hline History of $\mathrm{PCl}$ & -4.7 & -0.15 & 0.02 \\
\hline $\begin{array}{l}\text { Total no. of other } \\
\text { illnesses }\end{array}$ & -2.4 & -0.24 & 0.001 \\
\hline $\begin{array}{l}\text { Rehospitalization due } \\
\text { to heart disease }\end{array}$ & -6.3 & -0.24 & $\varangle 0.001$ \\
\hline
\end{tabular}

Table 4. Final Multivariate Linear Regression Model for MC S-12 Scores

\begin{tabular}{|c|c|c|c|}
\hline Variable & $\begin{array}{l}\text { Regression } \\
\text { Coefficient }\end{array}$ & $\begin{array}{c}\text { Standard } \\
\text { Regression } \\
\text { Coefficient }\end{array}$ & $p$ Value \\
\hline Age & 0.17 & 0.22 & 0.001 \\
\hline Compliance dichotomized & 6.60 & 0.24 & 0.001 \\
\hline Lipid-lowering therapy & 4.3 & 0.20 & 0.003 \\
\hline
\end{tabular}

MCS = M ental Component Summary.

study provides some insight into the efficacy of the SF-12 as a general measure of HRQOL in this population.

A number of predictor variables, primarily cardiac related, were associated with the PCS-12; these variables were obtained from a qualityassurance database used to monitor the care of patients in the health system. The relationship between a history of $\mathrm{PCl}$ and the index myocardial infarction may indicate severe heart disease and may have led to the lower physical HRQOL summary score. The lack of effect of revascularization procedures either during hospitalization or during the period between hospital discharge and the survey was somewhat unexpected. Other controlled trials found that revascularization procedures improve $\mathrm{HRQOL} .{ }^{14}$, 20-24 However, one group reported findings similar to ours, with need for revascularization being related to impaired HRQOL. ${ }^{4}$ Most often, study questionnaires were administered at the time of $\mathrm{PCl}$ and at some point after the procedure. This was different from our study, in which having had a $\mathrm{PCl}$ during hospitalization or interim period most likely represented a more severely ill patient.

A history of CHF or TIA before the index 
myocardial infarction was associated with lower PCS-12 scores. In fact, CHF was a major variable in one risk model, ${ }^{6}$ and the presence of TIA is known to be associated with reduced physical functioning. ${ }^{25}$ Being rehospitalized after the index myocardial infarction also had a negative association with the PCS-12 score, findings similar to another study in which subsequent stroke or reinfarction greatly impaired HRQOL. ${ }^{26}$ All three variables (CHF, TIA, rehospitalization due to cardiac reasons) indicate continuing cardiac and/or vascular illness and may represent advanced disease.

Women in this study had lower PCS-12 scores than men on univariate analysis, as reported in other studies of HRQOL after myocardial infarction. ${ }^{13,15,27}$ However, in our study, sex was eliminated from both PCS-12 and MCS-12 regression models, indicating a weaker relationship than the remaining variables.

Comorbidities had a negative association with PCS-12 scores. Simply having more comorbidities tends to lower HRQOL in all dimensions measured in patients with cardiac disease. ${ }^{13} \mathrm{~A}$ survey in a general population in a health district in Sweden found a negative association between number of chronic diseases and HRQOL. ${ }^{28}$ The impact was reduced slightly when adjusted for age but was still substantial. Thus researchers using general instruments such as the SF-12 must be aware of this effect.

The mental health domain was associated with age, with older age related to better mental health summary scores. This relationship was documented in SF-12 development as well as in independent assessments using respondents drawn from population studies and patients who experienced a recent myocardial infarction. ${ }^{13}$ Self-reported drug therapy compliance had a positive association with the mental health domain, in that patients with fewer depression-anxiety symptoms, as measured by MCS-12, had higher self-reported compliance. The negative relationship between depression and noncompliance is well documented. ${ }^{29}$ Depression after myocardial infarction that negatively affects HRQOL was reported in a number of studies ${ }^{1-3}$ and may be linked to increased morbidity and mortality. ${ }^{30,31}$ These patients should be monitored closely for drug compliance.

Of the four cardiac drugs examined in this study, only lipid-lowering agents were associated with an HRQOL measure in the regression models. Patients who had lower MCS-12 scores, indicating depressive and/or anxiety-related effects, were most likely to report that they were not taking these drugs, even when they were prescribed at discharge. Drug treatment for a relatively asymptomatic condition, elevated cholesterol, may be associated with lower compliance rates than other treatments for more symptomatic conditions such as ischemia after myocardial infarction. We did not assess patients for depression or anxiety using specific screening or diagnostic instruments, which may explain the limited amount of variance explained by the predictor variables in the final mental health regression model. In other studies depression was a significant predictor of HRQOL. ${ }^{6}$ Identification and treatment of depression or depressive symptoms may improve compliance and improve long-term benefits of treatment.

The ejection fraction did not have an association with either PCS-12 or MCS-12 scores. This is the same result as in another study, ${ }^{6}$ although one group reported a relationship between left ventricular ejection fraction and HRQOL, with lower ejection fraction predictive of lower HRQOL.13 One potential limitation in our study is that the ejection fraction was measured during or immediately after discharge from the hospital for the index myocardial infarction, whereas the questionnaire was administered approximately 7 months later. Thus changes in ejection fraction may have occurred that were not measured by the survey. Future studies to develop and validate selfreported measures of cardiac function would be useful when it is difficult to obtain objective data such as ejection fraction.

This study had several potential limitations. We included only one measure of HRQOL at approximately 7 months after myocardial infarction. Serial measures of HRQOL may have been able to detect changes that occurred immediately after discharge as well as 1 year and longer after the event. The fact that a baseline assessment was not performed allows only for an association rather than causality. Also not measured were symptoms related to ischemic heart disease and CHF. Similarly, patient perceptions of illness and disease severity, as well as noncardiovascular events, were not measured, and these variables may modify or influence patients' perception of change in functioning or HRQOL.

\section{Conclusion}

Health-related quality of life scores were low 7 
months after myocardial infarction. Physical scores (PCS-12) were especially lower for patients with more concomitant diseases; history of $\mathrm{PCl}, \mathrm{CHF}$, or TIA; and rehospitalization in the interim period. Mental scores (MCS-12) were significantly lower for those younger than 65 years and those reporting lower overall compliance with drug therapy, lipid-lowering therapy in particular. After a patient has a myocardial infarction, particular attention should be paid to the patient's cardiovascular medical history. Further work is necessary to determine noncardiovascular predictors of quality of life and whether interventions aimed at these patients will result in improved quality of life.

\section{References}

1. Spertus JA, McDonnell M, Woodman CL, Fihn SD. Association between depression and worse disease-specific functional status in outpatients with coronary artery disease. Am Heart J 2000;140:105-10.

2. Plevier CM, Mooy JM, Marang-VandeMheen PJ, et al. Persistent impaired emotional functioning in survivors of a myocardial infarction? Qual Life Res 2001;10:123-32.

3. Lane D, Carroll D, Ring C, Beevers DG, Lip GYH. Mortality and quality of life 12 months after myocardial infarction: effects of depression and anxiety. Psychosom Med 2001;65:221-30.

4. Brown N, Melville M, Gray D, et al. Quality of life four years after acute myocardial infarction: short form 36 scores compared with a normal population. Heart 1999;81:352-8.

5. Crilley JG, Farrer $\mathbf{M}$. Impact of first myocardial infarction on self-perceived health status. Q J Med 2001;94:13-18.

6. Rumsfeld JS, Magid DJ, Plomondon ME, et al. Predictors of quality of life following acute coronary syndromes. Am J Cardiol 2001;88:781-4.

7. Heller RF, Lim L, Valenti L, Knapp J. Predictors of quality of life after hospital admission for heart attack or angina. Int J Cardiol 1997;59:161-6.

8. Obrien BJ, Buxton MJ, Patterson DL. Relationship between functional status and health-related quality-of-life after myocardial infarction. Med Care 1993;31:950-5.

9. Westin L, Carlsson R, Israelsson B, Willenheimer R, Cline C, McNeil TF. Quality of life in patients with ischaemic heart disease: a prospective controlled study. J Intern Med 1997; 242:239-47.

10. Valenti L, Lim L, Heller RF, Knapp J. An improved questionnaire for assessing quality of life after acute myocardial infarction. Qual Life Res 1996;5:151-61.

11. Wingate $\mathbf{S}$. Quality of life for women after a myocardial infarction. Heart Lung 1995;24:467-73.

12. Beck CA, Joseph L, Belisle P, Pilote L. Predictors of quality of life 6 months and 1 year after acute myocardial infarction. Am Heart J 2001;142:271-9.

13. Coyne KS, Lundergan CF, Boyle D, et al. Relationship of infarct artery patency and left ventricular ejection fraction to health-related quality of life after myocardial infarction. Circulation 2000;102:1245-51.

14. Mark DB, Naylor CD, Hlatky MA, et al. Use of medical resources and quality of life after acute myocardial infarction in Canada and the United States. N Engl J Med 1994;331:1130-5.

15. Covinsky KE, Chren MM, Harper DL, Way LE, Rosenthal GE Differences in patient-reported processes and outcomes between men and women with myocardial infarction. J Gen Intern Med 2000;15:169-74.

16. Lim LL, Johnson NA, OC onnell RL, Heller RF. Quality of life and later adverse health outcomes in patients with suspected heart attack. Aust N Z J Public Health 1998;22:540-6.

17. Hillers TK, Guyatt GH, Oldridge N, et al. Quality of life after myocardial infarction. J Clin Epidemiol 1994;47:1287-96.

18. Morisky DE, Green LW, Levine DM. Concurrent and predictive validity of a self-reported measure of medication adherence. Med Care 1986;24:67-74.

19. Ware JE, Kosinski M, Keller SD. SF-12: how to score the SF-12 physical and mental health summary scales, 2nd ed. Boston: Health Institute, N ew England Medical Center, 1995.

20. Mortensen OS, Madsen JK, Haghfelt $T$, et al. Health related quality of life after conservative or invasive treatment of inducible postinfarction ischaemia. Heart 2000;84:535-40.

21. Allen JK, Fitzgerald ST, Swank RT, Becker DM. Functional status after coronary artery bypass grafting and percutaneous transluminal coronary angioplasty. Am J Cardiol 1990; 65:921-5.

22. Herlitz J, Wiklund I, Sjoland $\mathbf{H}$, et al. Relief of symptoms and improvement of quality of life five years after coronary artery bypass grafting in relation to preoperative ejection fraction. Qual Life Res 2000;9:467-76.

23. Pocock SJ, Henderson RA, Seed P, Treasure T, Hampton JR Quality of life, employment status, and anginal symptoms after coronary angioplasty or bypass surgery. Circulation 1996; $94: 135-42$.

24. Brorsson B, Bersnstein SJ, Brook RH, Werko L. Quality of life of chronic stable angina patients 4 years after coronary angioplasty or coronary artery bypass surgery. J Intern Med 2001;249:47-57.

25. Duncan $\mathbf{P}$, Samsa GP, Weinberger $\mathbf{M}$, et al. Health status of individuals with mild stroke. Stroke 1997;28:740-5.

26. Glasziou PP, Bromwich S, Simes RJ. Quality of life six months after myocardial infarction treated with thrombolytic therapy. AUS-TASK group. Med J Aust 1994;161:532-6.

27. Burdine JN, Felix MRJ, Abel AL, Wiltraut CJ, Mussleman $Y$ J. The SF-12 as a population health measure: an exploratory examination of potential for application. Health Serv Res 2000;35:885-904.

28. Michelson $\mathbf{H}$, Bolund C, Brandberg Y. Multiple chronic health problems are negatively associated with health related quality of life (HRQoL) irrespective of age. Qual Life Res 2001;9: 1093-1104.

29. DiMatteo MR, Lepper HS, Croghan TW. Depression is a risk factor for noncompliance with medical treatment. Arch Intern Med 2000;160:2101-7.

30. Frasure-Smith $\mathbf{N}$, Lesperance $\mathbf{F}$, Talajic $\mathbf{M}$. Depression following myocardial infarction. Impact on 6-month survival. JAM A 1993;279:1819-25.

31. Lesperance F, Frasure-Smith N, Talajic M, Bourassa MG. Fiveyear risk of cardiac mortality in relation to initial severity and one-year changes in depression symptoms after myocardial infarction. Circulation 2002;105:1049-53. 